\title{
The effect of educational intervention based on the integrated model of health belief with the structure of social support on self-care behaviors during pregnancy
}

\begin{abstract}
Background and Objective: Self-care behaviors during pregnancy can be effective in reducing the adverse consequences of pregnancy. The aim of this study was to investigate the effect of educational intervention based on the integrated model of health belief model with the structure of social support on self-care behaviors during pregnancy.

Materials and Methods: The present study was a quasi-experimental study conducted among 90 pregnant women in the first abdomen of Iranshahr in 2017. The samples were selected by simple random sampling and divided into two groups of intervention ( 45 people) and control ( 45 people). 5 training sessions were held for the intervention group and no intervention was performed in the control group. Six months after the training intervention, the questionnaire was completed by both groups. The collected data were analyzed using SPSS software version 20 and independent $\mathrm{t}$-test, paired t-test and chi-square test.

Results: The results showed that the mean scores of pregnant mothers in Perceived susceptibility structures $1.74( \pm 0 / 17)$, Perceived severity $4.55( \pm 0 / 05)$, Perceived benefits $0.63( \pm 0 / 05)$, self-efficacy $3.67( \pm 0 / 41)$, social support structure $5.13( \pm 0 / 63)$ and self-care behaviors $3.15( \pm 0 / 38)$ showed a significant increase in the intervention group $(p<0.001)$. In the comparison of birth weight, there was a statistically significant difference between the intervention and control groups after the educational intervention $(P=0.036)$.

Conclusion: The combination of health belief model and social support structure can be used as a suitable framework for designing and implementing educational interventions aimed at promoting the self-care behaviors of pregnant women and birth weight.

Keywords: Self-care, Social support, Health Belief Model, Birth weight, Pregnant women

Paper Type: Research Article.
\end{abstract}

Citation (Vancouver): Izadirad H, Nohtani V, Aliahmadi M, Pourhaji F, Niknami $\mathrm{SH}$. The effect of educational intervention based on the integrated model of health belief with the structure of social support on self-care behaviors during pregnancy . Iran J Health Educ Health Promot. Winter 2021;8(4):324-335. [Persian]x

> Citation (APA): Izadirad H., Nohtani V., Aliahmadi M., Pourhaji F., Niknami SH. The effect of educational intervention based on the integrated model of health belief with the structure of social support on self-care behaviors during pregnancy. Iranian Journal of Health Education \& Health Promotion., 8(4),324-335 . [Persian]
Hossien Izadirad

Assistant Professor, Health Education and Health Promotion Department. Zahedan university Medical sciences, Zahedan, Iran

Vahid Nohtani

* M.Sc. Student of Health Education and Health Promotion, Faculty of Health Sciences, Zahedan University of Medical Sciences, Zahedan Iran. (Corresponding author):

V.Nohtani2000@gmail.com

Mahdi Aliahmadi

M.Sc. Student of Health Education and Health Promotion, Faculty of Health Sciences, Zahedan University of Medical Sciences, Zahedan Iran.

Fatemeh Pourhaji

Assistant Professor, Health Education and Health Promotion Department, Faculty of Health Sciences, Torbat Heydariyeh University of Medical Sciences, Torbat Heydariyeh, Iran.

Shamsoddin Niknami Associate Professor, Health Education and Health Promotion Department, Tarbiat Modarres University, Tehran, Iran.

Received: 2020/04/16

Accepted: 2020/09/03

Doi: 10.29252/ijhehp.8.4.1 


\section{تأثير مداخله آموزشى مبتنى بر الكَوى باور سلامت و ساختار حمايت اجتماعى بر رفتارهاى خودمراقبتى دوران باردارى ساخت}

حسين ايزدى راد

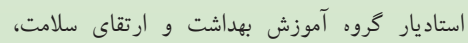
دانشكاء علوم بزشكى زاهدان، ايران.

$$
\text { وحيد نهتانى دانى }
$$

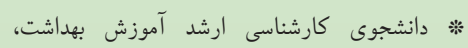

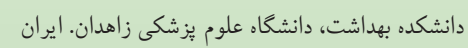
V.Nohtani2000@gmail.com

$$
\text { ( نويسنده مسول) }
$$

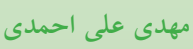
دانشجوى كارشناسى ارشد آموزش بهداشت، دانشكده بهداشت، دانشگاه علوم بز شكى زاهد اندان.ايران

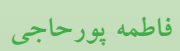

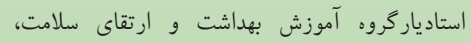

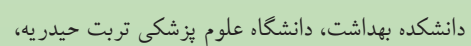

ايران

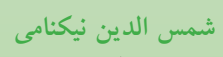
استاد كروه آموزش بهداشت و ارتقاى سلامت، دانشكدا. يزشكى، دانشكاه تربيت مدرس تهران، تهران، ايران.

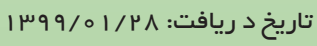

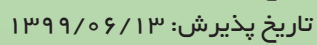

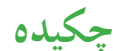

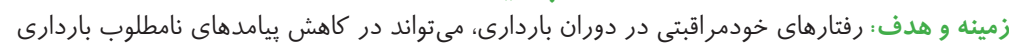

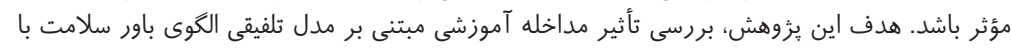

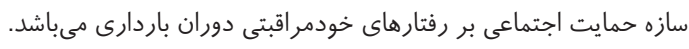

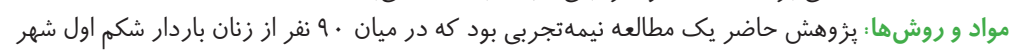

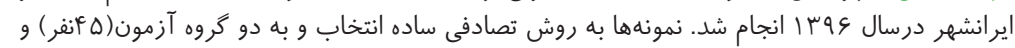

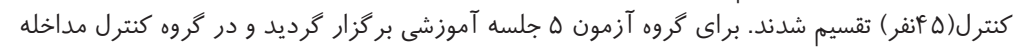

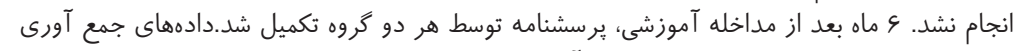

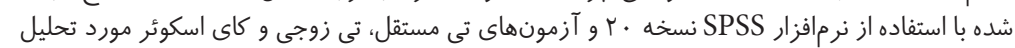
قرار گرفتند.

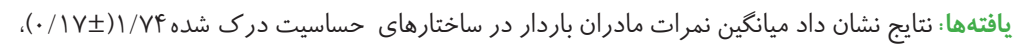

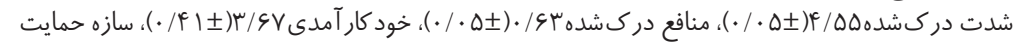

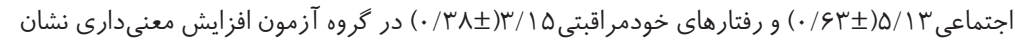

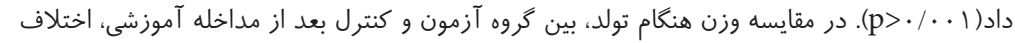

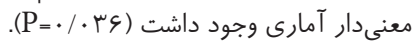

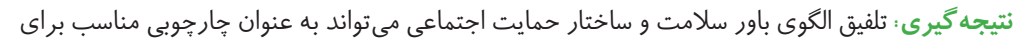

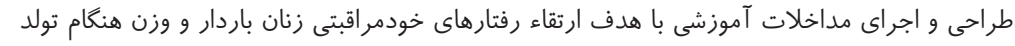

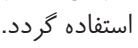

كليدواره: خودمراقبتى، الكوى باود سلامت، حمايت اجتماعى، وزن هنغام تولد، زنان باردار

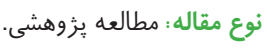

> استناد (ونكوور): ايزدى راد ح، نهتانى و، على احمدى م، يور حاجى ف، نيكنامى ش. تأثير مداخله

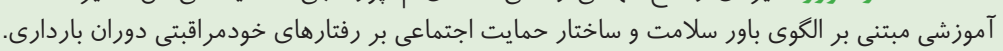

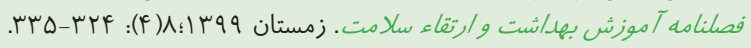

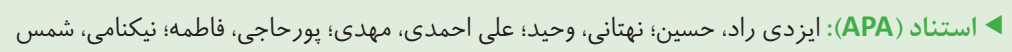

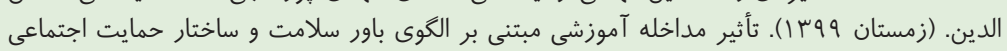

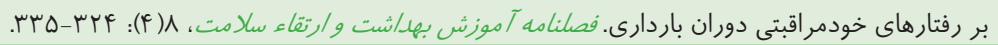


شمال خوزستان ( (r/Y\%) است( • ) . فقدان خودمراقبتى و حمايت

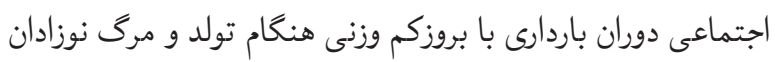

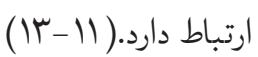

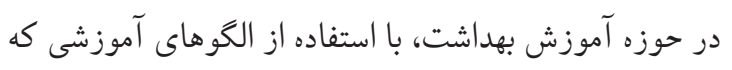
براى تبيين عوامل مرتبط با رفتار طراحى شدهاند و بررسى ميزان

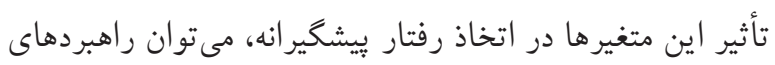

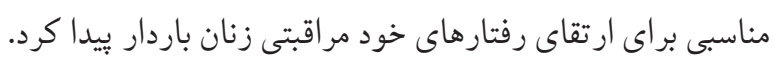

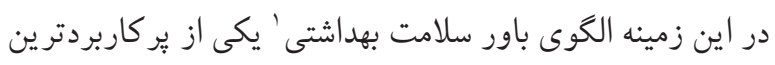

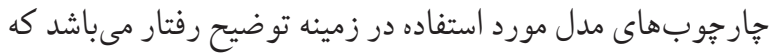

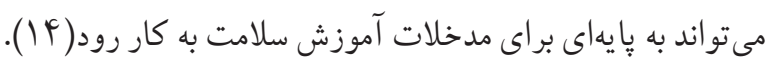

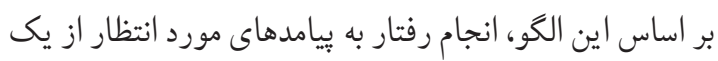

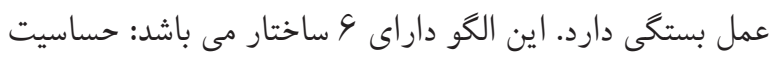

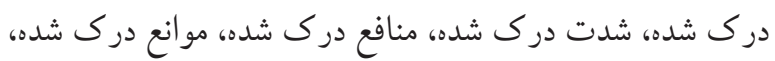

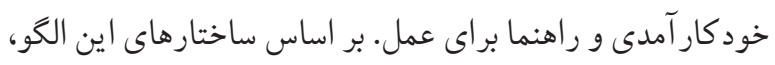

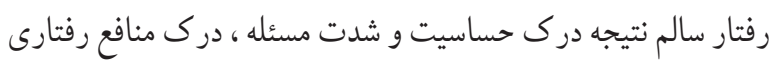

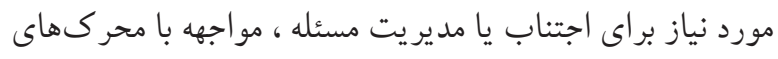

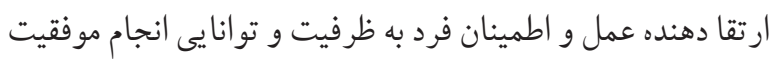

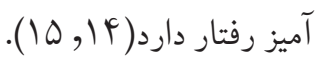
اكر جه بارها نقش آكاهى و نكخرش بر خودمر اقبتى مورد توجه

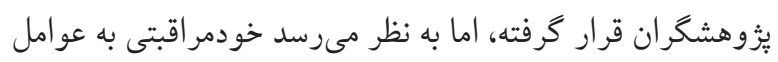

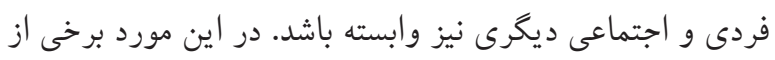

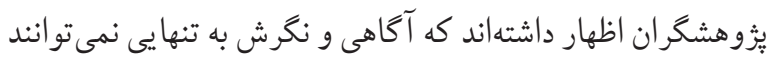

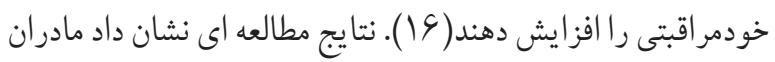

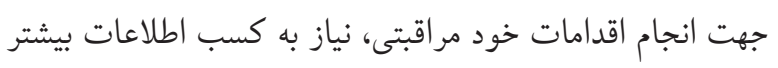

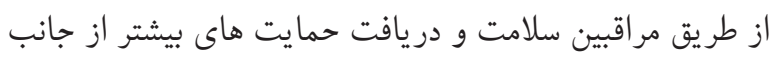

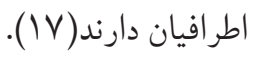

يكى از عوامل اجتماعى تعيين كننده سلامت كه به اهميت بعد الماند

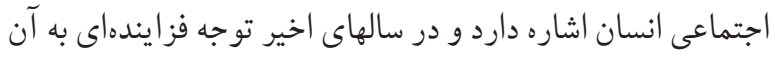

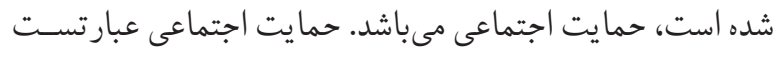

تغييرات هيجانى، جسمانى و اجتماعى ناشى از باردارى سبب تغيير در

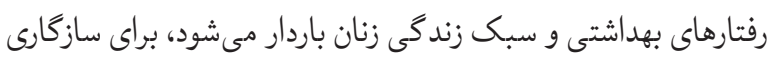

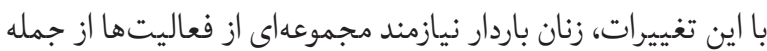
خود مراقبتى و حمايت اجتماعى مى باشند ( ). خودمراقبتى دوران باردارى به تصميمات و فعاليت هايى اشاره مى كند كه يك فرد باردار

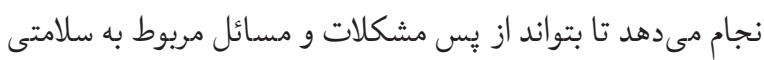

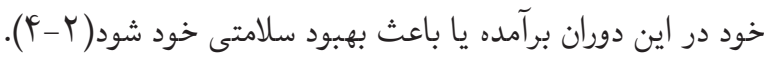
بــراى اثــربخش بـودن خـود مراقبتسى دوران باردارى، زنان باردار

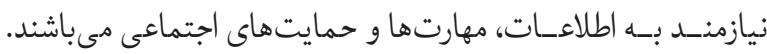
زنان باردار خصوصاً زنان جوان نياز دارند تا براى مراقبت از خوان خود در

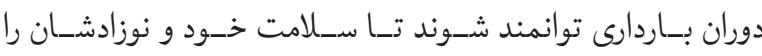

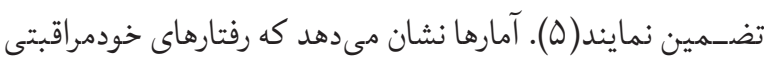

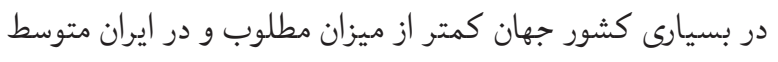

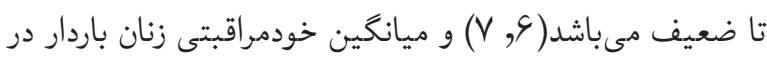

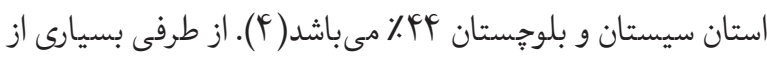
ييامدهاى نوزادى از جمله وزن هنكام تولد وابسته به خودمراقبتى

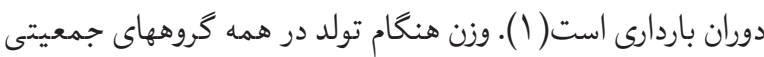
بيشترين اهميت در تعيين شانس بقاو تجربه يك رشد و نمو سالم را برعهده دارد. هيج شاخصى در زندگى انسان ماندو وزن هنكام تولد

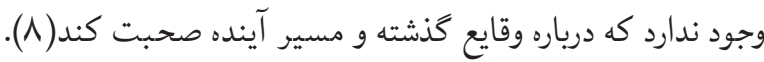

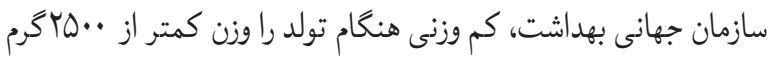

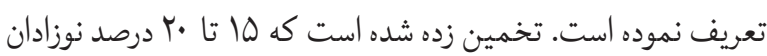
دنيا داراى كم وزنى هستند كه بيش از •† ميليون تولد در سال را

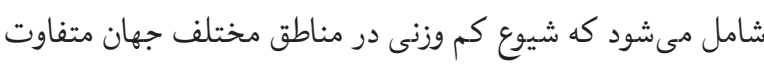

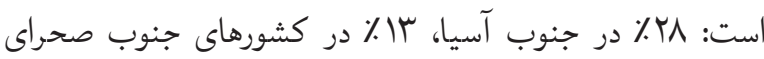

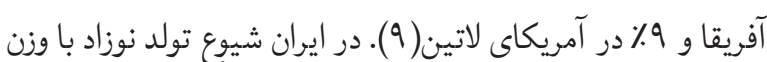

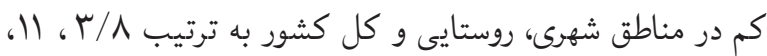

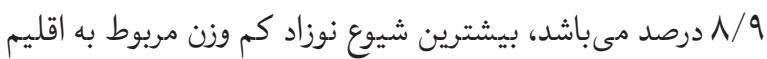

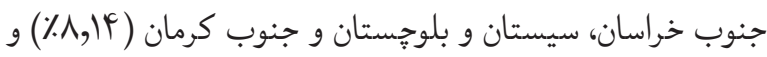
كمترين آن در اقليم كردستان، همدان، لرستان، كرمانشاه، ايلام و و وران 
دوران باردارى يُيجيده بوده و علاوه بر عوامل فردى، تحت تاثير

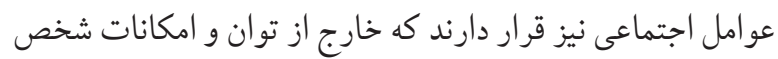

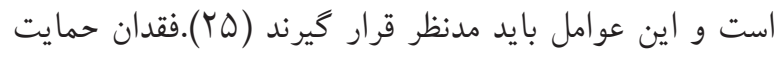
اجتماعى به عنوان يك فاكتور خطر مهم سلامت مادر در دوران

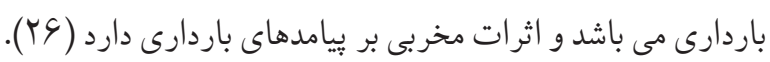

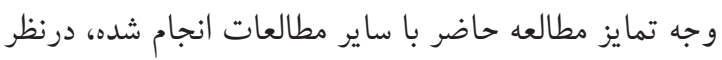

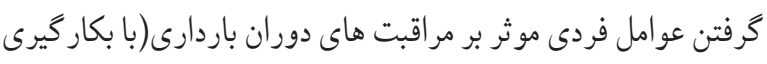
الكوى باور سلامت) و همجنين حمايت اجتماعى ( بكاربردن ساختار

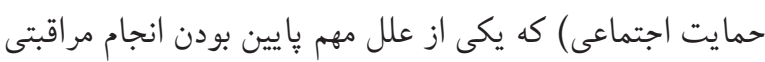
دوران باردارى از نظر گروه هدف بود، مى توان بيان نمود.

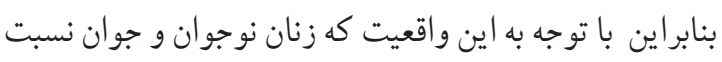

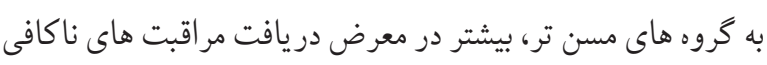

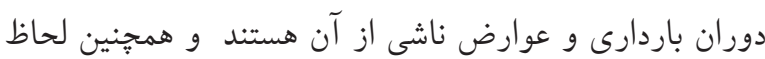
نمودن عوامل فردى و اجتماعى در بهبود رفتارهاى مراقبتى دوران باردارى علاوه بر الكوى باور سلامت، ساختار حمايت اجتماعى از

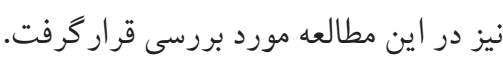

$$
\text { روش كار }
$$

مطالعه حاضر از نوع نيمه تجربى بود (IRCT2017030432876N1).

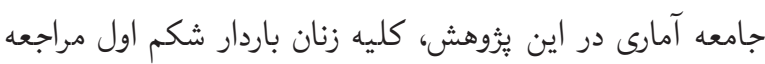

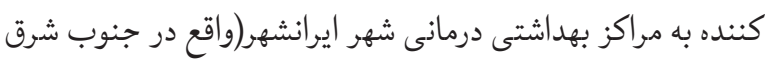

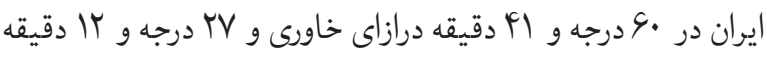
يهناى شمالى و درقسمت مركزى استان سيستان و بلوجستان) بود. مطالعه از ارديبهشت و9ها شروع و در آذر همان سال خاتمه يافت.

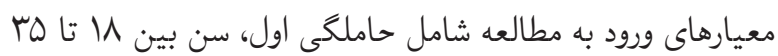
سالخى(با توجه به ويزگى هاى فرهنگى و اقتصادى، ازدواج در منطقه بلوجستان ، بخصوص مناطق روستايى و عشايرى در سنين بايينتر از

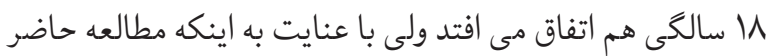
در شهر انجام شده، موارد باردارى در سنين كمتر از ل ل مشاهده نشد. باردارى هاى زير \1 بيشتر در سطح روستاها مشاهده مى بـ شود)، قرار داشتن مادران در سه ماهه اول باردارى، داشتن برونده
از آرامش احساسـى و جسـمانى كه خانو اده، دوسـتان يا همكاران و بقيـه افراد بـه فرد مىدهند. حمايـت اجتماعى يعنى دانسـتن اين

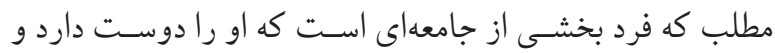

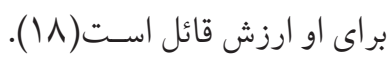

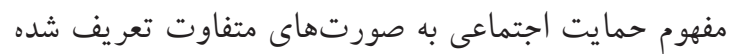

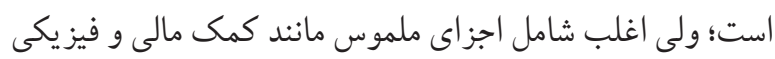
و غير ملموس مانند تشويق و راهنمايى مىشوند. ايسن حمايست

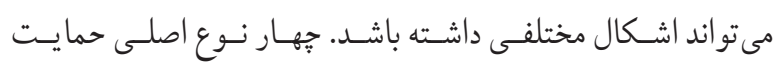
اجتماعسى وجسود دارد: إهـ - حمايت ابزارى شامل منابع مادى مانند

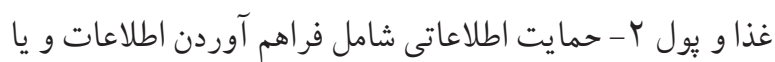
ييشنهادات است و فرد را قادر مى سازد تا با مشكلات و سختىها

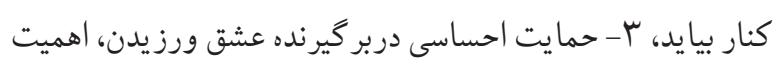

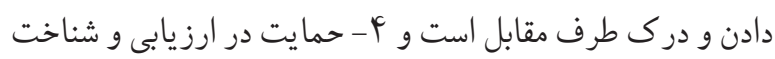

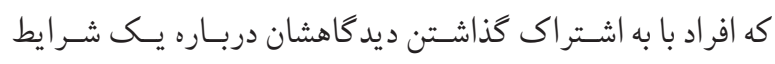

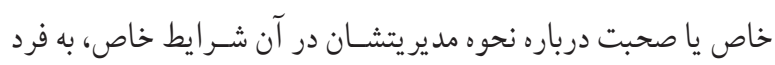

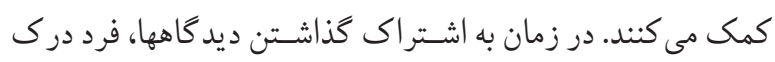

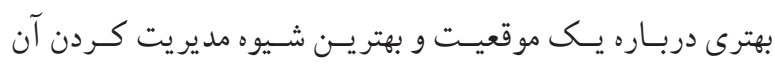

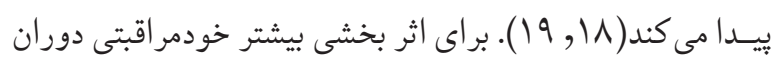

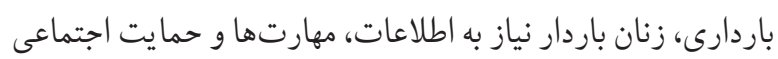

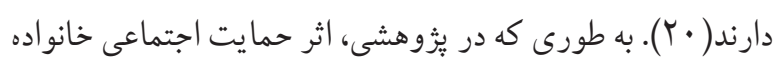

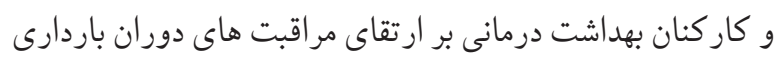
بر اهميت شمرده شده است( (T). نظريه شناختى اجتماعى از جمله تئورىهايى است كه در تحقيقات مر تبط خودمر اقبتى استفاده شده است، طبق اين تئورى عوامل شناختى، فاكتورهاى عوامل محيطى تُونى

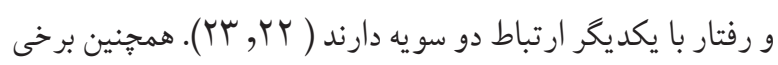

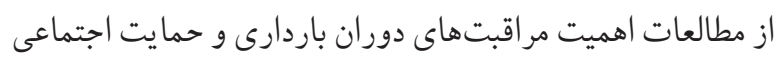
را براى سلامت مادر و نوزاد مهم تلقى كردهاند(Y) (Y).

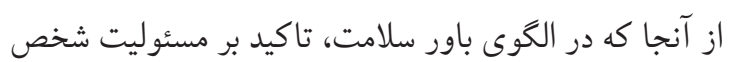

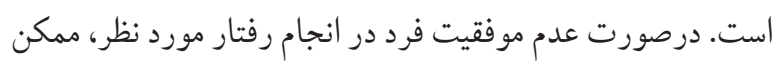

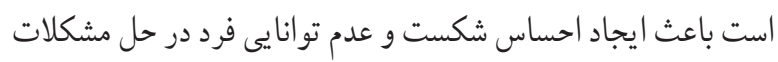

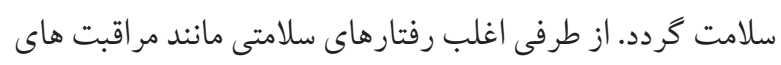


مشتمل بر اطلاعات جمعيت شناختى، ساختارهاى الكوى باور سلامت، حمايت اجتماعى و رفتارهاى مراقبتى دوران باردارى بود. اين

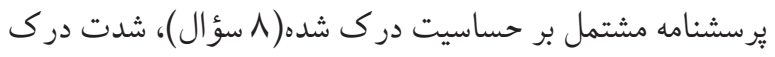

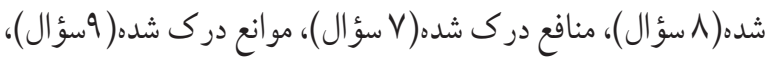

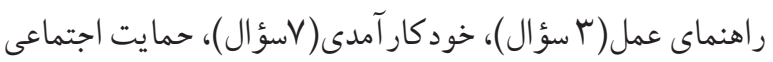

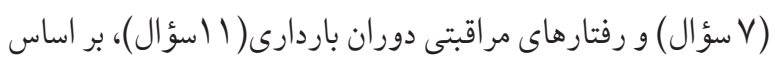
مقياس ليكرت با طيف سه تايى مورد سنجش قرار كر فتند. روايى

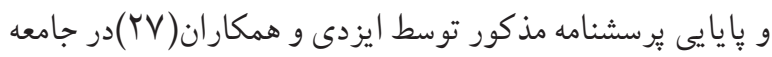

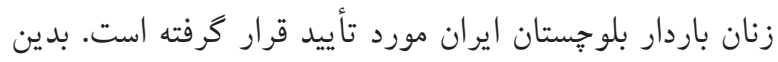

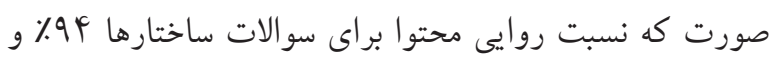

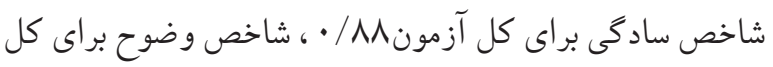

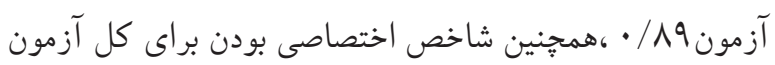

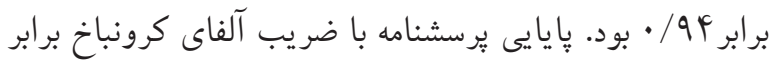

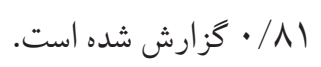

مو لفه هاى مورد سنجش در ساختار حمايت اجتماعى شامل تهيه مو اد غذايى مناسب دوران باردارى، تامين مخارج انجام آزمايشات دردات

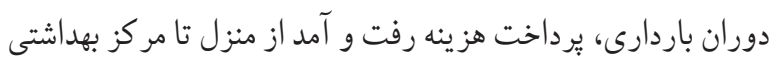

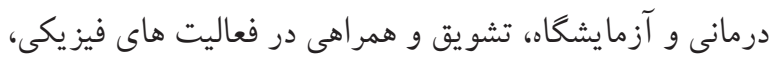
تشويق جهت انجام مراقبت هاى دوران باردارى و حمايت اطلاعاتى دانى

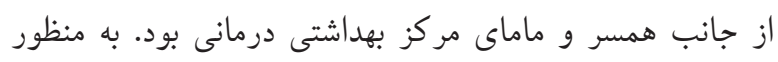

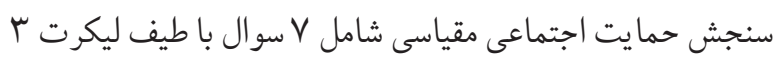

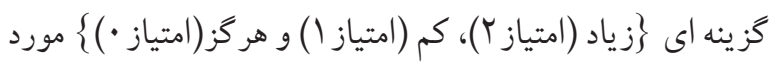
استفاده قرار كرفت. نحوه اجراى يُووهش به اين صورت بود كه پِ آس از انتخاب دو

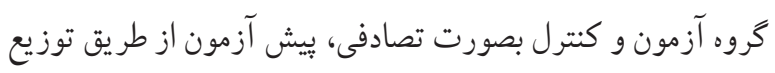

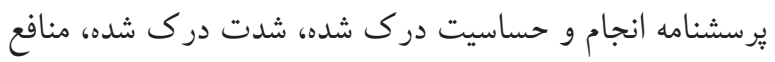

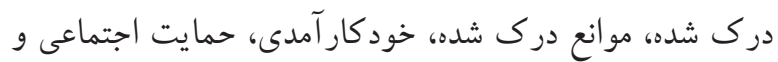

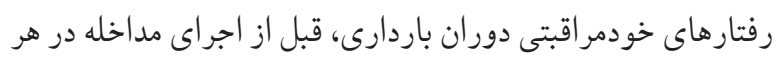

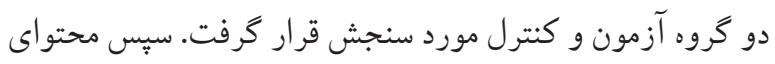

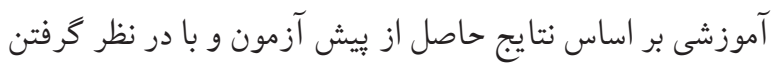

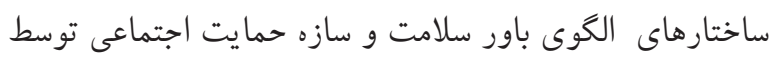

مراقبتى و برخوردارى زن از سلامت بود. معيارهاى خروج از مطالعه شامل سقط جنين، مهاجرت و نياز به مراقبت ويثه بود. تعداد نمونه جهت مطالعه، با توجه به تحقيق انجام شده در زمينه مشابه مطالعه حاضر(怆)، در استان سيستان و بلوجستان، حجم نمونه با سطح

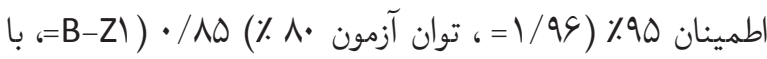

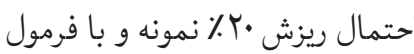

$$
n=\frac{\left(Z_{1-\alpha / 2}+Z_{1-\beta}\right)^{2}\left(S_{1}^{2}+S_{2}^{2}\right)}{\left(\mu_{1}-\mu_{2}\right)^{2}}
$$

انحراف معيار متغير مورد مطالعه در كروه اول (مورده، S, مواجهه يافته يا مداخله) أنحر اف معيار متغير مورد مطالعه در كروه دوم (شاهد، غيرمواجهه يافته با مقايسه)

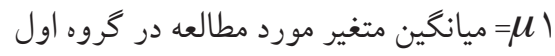

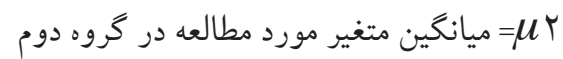

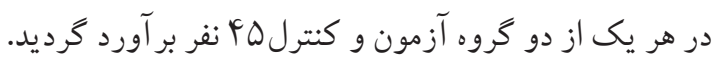

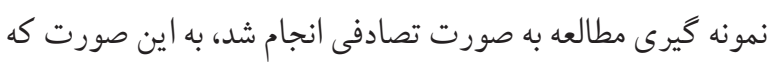

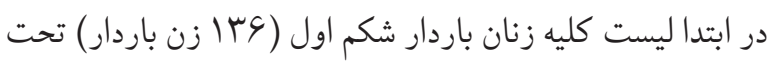
يوشش ه مر كز بهداشتى درمانى شهرى ايرانشهر (كل مر اكز بهداشتى

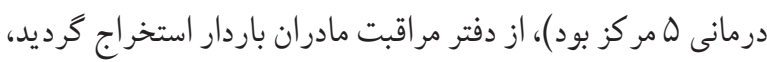

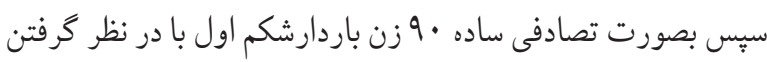

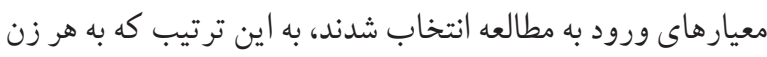

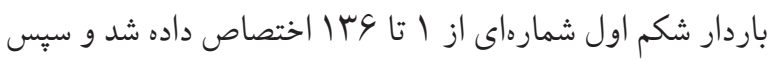

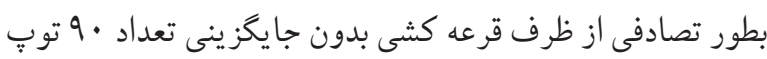

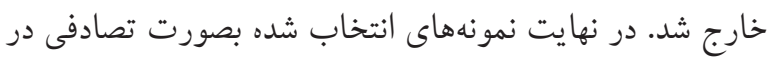

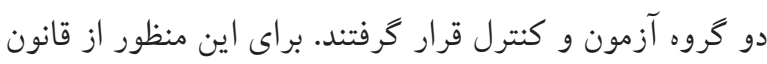

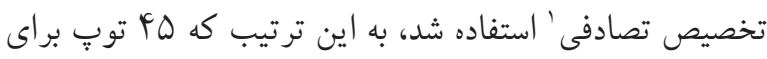

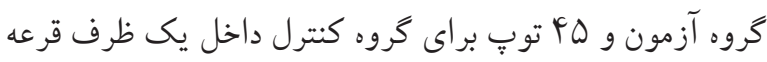

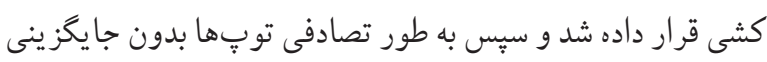

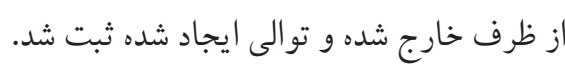

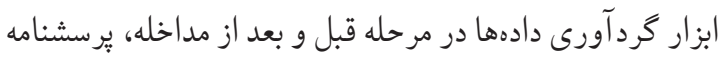


شوهران با موانع مطرح شده جهت انجام مراقبتهاى دوران باردارى

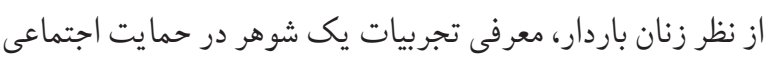
از زنان باردار و بحث در خصوص توانيى شوهران جهت حمايت بنايت

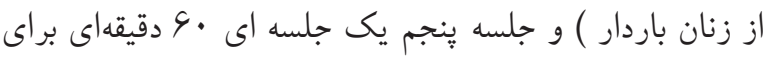

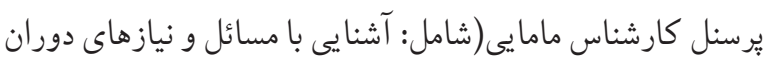

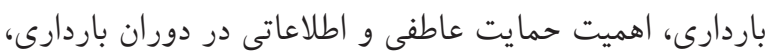

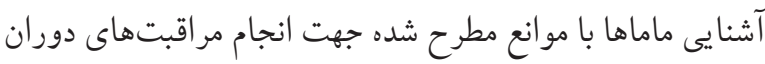

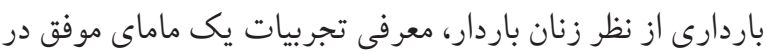
حمايت اجتماعى از زنان باردار و بحث در خصوص توانايى ماماها

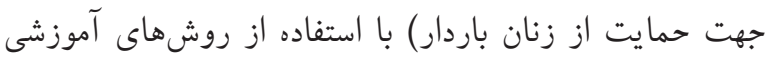
سخنرانى، يرسش و پاسخ، بحث كروهى و ايفاى نقش در سالن اجتماعات مركز بهداشت بركزار كرديد. (از علل كم بودن تعداد

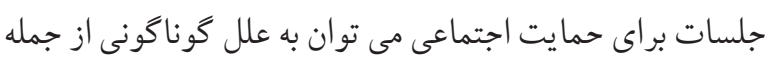

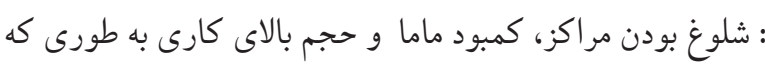

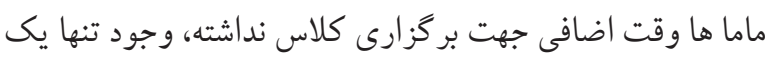

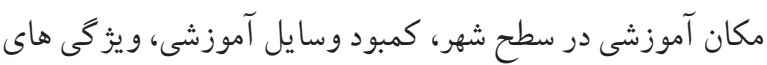

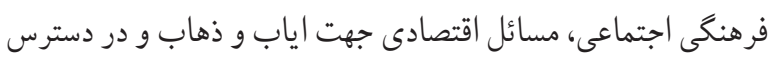

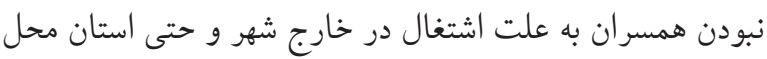

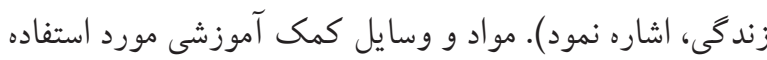
در برنامه عبارت بودند از وايت برد، فيلم و كتابجه. به منظور بررسى تداوم انجام رفتارهاى بهداشتى در ماه هاى

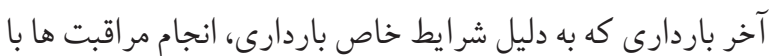

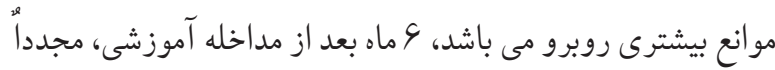
همان يرسشنامه توسط افراد تكميل شد و ميزان تغييرات در زمينه ساختارهاى الخوى باور سلامت، حمايت اجتماعى و رفتار(مر اقبتهاى

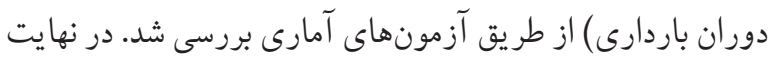

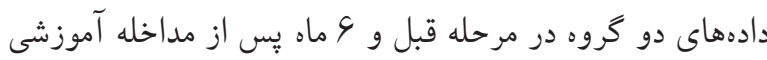

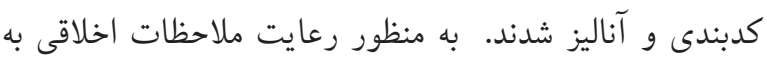

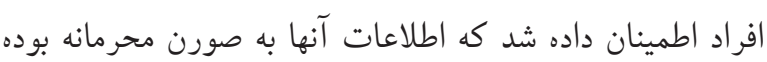
و براى هريك از شر كت كندكان فرم رضايت آكاهانه تكميل

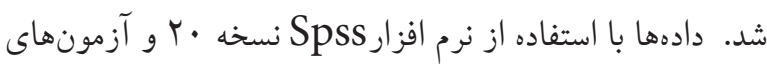

يُزوهشكر تهيه، تنظيم شد و توسط كارشناس مامايى اجرا كرديد.

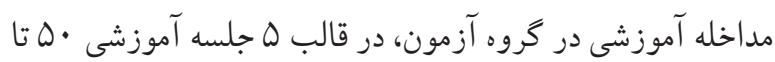

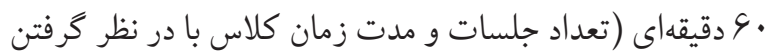
شرايط اجتماعى، فرهنكى گروه هدف و قابليت اجرايى در مراكز

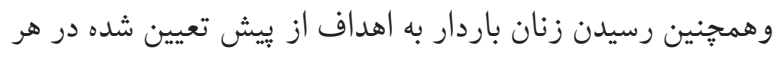

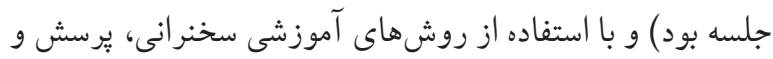

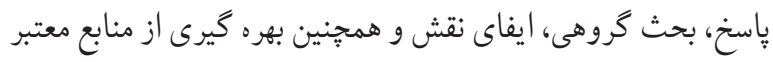

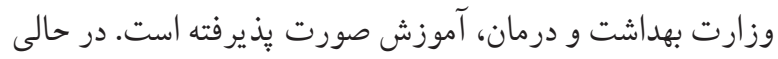

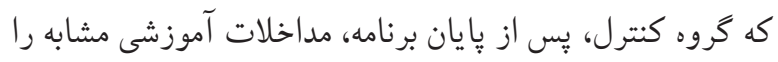

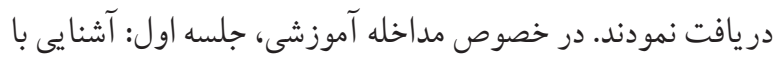
مر اقبتهاى دوران باردارى، زمان شروع مر اقبتها، نكات بهداشتى،

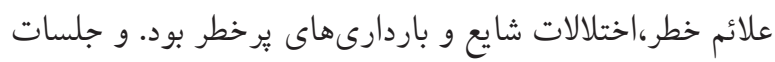

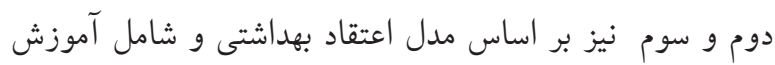
در جهت بالا بردن حساسيت و شدت درك شده مادران در زمينه

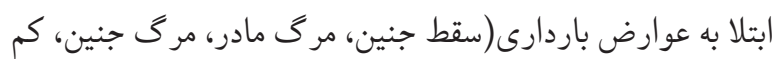

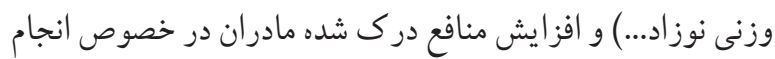
مر اقبتهاى دوران باردارى و همجنين تلاش در جهت كاهش موانع

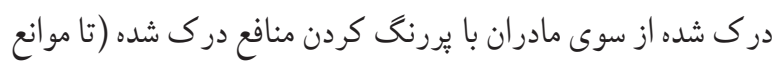

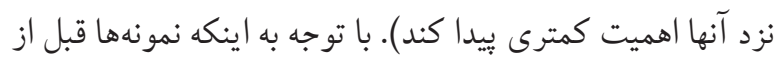

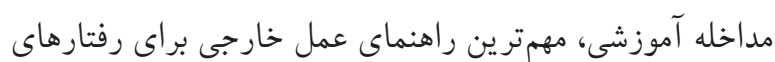
مر اقبتى دوران باردارى خود را ماما عنوان كرده بو دند سعى شد در دراي

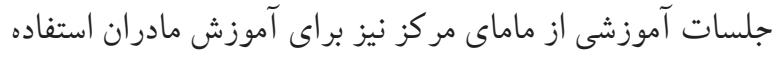

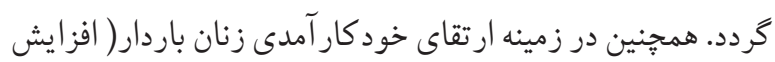

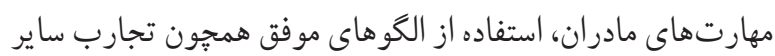
مادران شكم اولى كه موفق به انجام خودمر اقبتى در همان جامعه و با شر ايط مشابه شدهاند، فيلم آموزشى، تنظيم برنامه زمانبندى شدرد

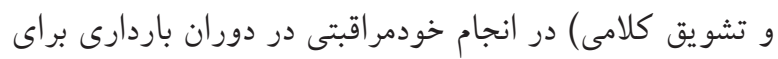

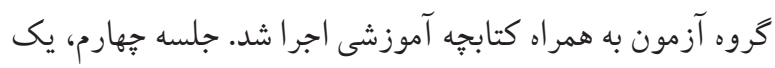

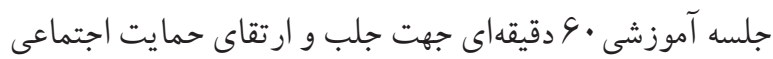

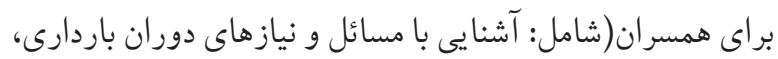
اهميت حمايت عاطفى، مالى و اطلاعاتى در دوران باردارى، آشنايى 
بر اساس آزمون تى مستقل، قبل از مداخله بين ميانكين سن، آكاهى و ساختارهاى الخوى باور سلامت ، ساختار حمايت اجتماعى و رفتارهاى مراقبتى دوران باردارى، اختلاف آمارى معنادارى مشاهده

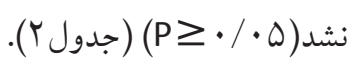

جدول r. مقايسه ميانگين متغير هاى سن، آكَاهى، سازه هاى مدل

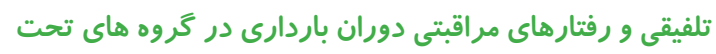
مطالعه قبل از مداخله آموزشى دوري

\begin{tabular}{|c|c|c|c|c|c|}
\hline \multirow[b]{2}{*}{ معنى دارى } & \multicolumn{2}{|c|}{ كروه كنترل } & \multicolumn{2}{|c|}{ كروه آزمون } & \multirow[b]{2}{*}{ متغير } \\
\hline & ميانگين & انحراف & ميانگين & انحراف & \\
\hline *./rq1 & rl & $(r / 9 V)$ & $r \cdot / v \wedge$ & $(Y / \mid \Lambda)$ & سن \\
\hline rir/r & $f \cdot / 9$ & $(s / \mid \mu)$ & $\mu q / . \varphi$ & $(\Lambda / \Delta)$ & آكاهى \\
\hline$\cdot / V F \Delta$ & Ir/Vr & $(\mathrm{l} / \wedge \mathrm{\vee})$ & Ir/As & $(r)$ & حساسيت درى \\
\hline . /OrV & $1 \cdot / k r$ & $(r / r \Delta)$ & 1./Ar & $(\Gamma / \Delta s)$ & شدت درك شده \\
\hline$\cdot / r \mid 1$ & Ir/Ar & $(r / \Delta S)$ & Ir/rv & $(1 / \uparrow c)$ & منافع درك شده \\
\hline.$/ 910$ & $\Lambda / T_{1}$ & $(r / \cdot \Delta)$ & $\Lambda / r V$ & $(r / \Lambda \mu)$ & موانع درى شده \\
\hline$\cdot / r \cdot V$ & q/^r & $(1 / \Delta \varsigma)$ & $q / \vee \Delta$ & $(1 / \Delta \Lambda)$ & خود كار آمدى \\
\hline •/Vqu & $1 \cdot / 9 r$ & $(1 / r \Delta)$ & $1 \cdot / V 1$ & $(1 / 11)$ & حمايت اجتماعى \\
\hline .1941 & $\mid r / 90$ & $(1 / \Delta \Delta)$ & $\mid r / g r$ & $\left(r / \varsigma^{\mu}\right)$ & رفتارهاى مراقبتى \\
\hline
\end{tabular}

براى تعيين اثربخشى مداخله آموزشى از طريق مقايسه ميانگين

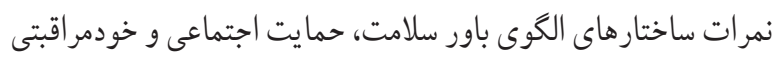

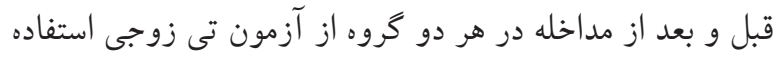

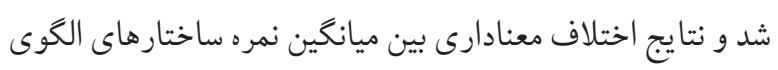
باور سلامت، حمايت اجتماعى و خودمراقبتى قبل و بعد از مداخله

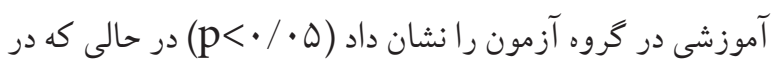

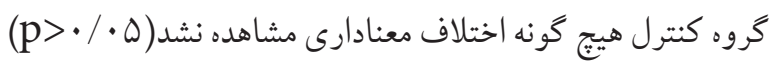

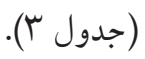
همانكونه كه در جدول F أ مشاهده مىشود، در مقايسه وزن

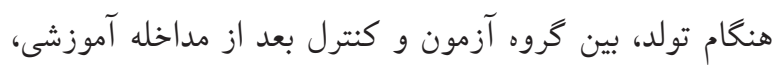

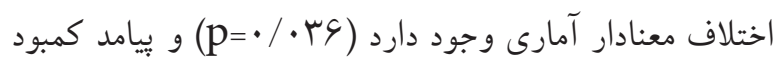

آمارى توصيفى و تحليلى و آزمون تى مستقل، تى زوجى و كاى

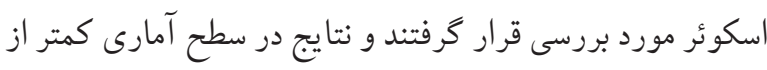

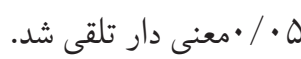

يافتهها

با توجه به تمهيدات صورت گرفته ميزان ريزش نمونه ها صفر

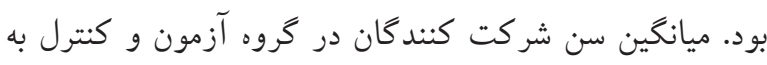

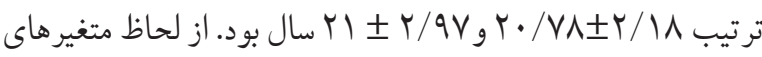
جمعيت شناختى، تفاوت معنى دارى بين دو گروه آزمون و كنترل

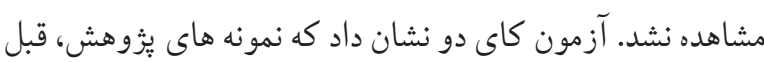

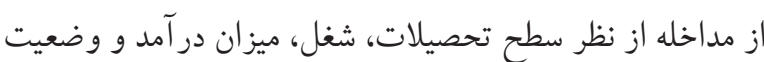
بيمه با هم اختلاف معنى دارى نداشتند(جدول ال). جدول ا. مقايسه مشخصات دمو گرافيك در گروه هاى تحت مطالعه قبل از مداخله آموزشى دموكي

\begin{tabular}{|c|c|c|c|}
\hline معنى دارى" & تعروه كنترل & تعروه آزمون & 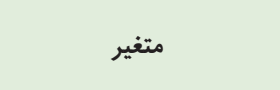 \\
\hline \multirow{4}{*}{.1990} & & & سطح تحصيلات \\
\hline & $I V(r \vee / V \vee)$ & $19(F r / r Y)$ & ابتدايى و راهنمايى \\
\hline & $r \cdot(F F / F F)$ & $\mid \Lambda\left(F_{\cdot} \cdot\right)$ & دبير ستان \\
\hline & $\Lambda(\mid V / V \vee)$ & $\Lambda(\mid \vee / V V)$ & دانشگاهى \\
\hline \multirow{3}{*}{1} & & & 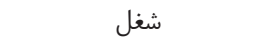 \\
\hline & $P \mid(q 1 / 1 Y)$ & $F \mid(q 1 / 1 r)$ & خانه دار \\
\hline & $F(\Lambda / \Lambda \Lambda)$ & $F(\Lambda / \wedge \Lambda)$ & 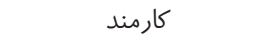 \\
\hline \multirow{4}{*}{$\cdot / s \checkmark$. } & & & ميزان در آمد ماهيانه خانوار \\
\hline & $\mu \cdot(\varsigma \varnothing / \varsigma \varnothing)$ & $r \varphi(\Delta V / V V)$ & كمتر از ..0 هزار تومان \\
\hline & $1 \cdot(r Y / r Y)$ & $\mid r(Y S / G G)$ & بين · •ه هزار تا ا ميليون \\
\hline & $\Delta(11 / 11)$ & $V(\backslash \Delta / \Delta \Delta)$ & بين ا تا r ميليون \\
\hline \multirow{3}{*}{$\cdot$ /Vro } & & & وضعيت بيمه \\
\hline & $r \cdot(\wedge \Lambda / \wedge \Lambda)$ & $F \mid(91 / 1 r)$ & 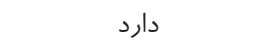 \\
\hline & $\Delta(11 / 1 r)$ & $F(\Lambda / \wedge \Lambda)$ & 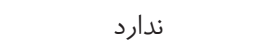 \\
\hline
\end{tabular}


جدول س. مقايسه ميانگين ساختارهاى الكوى باور سلامت، ساختار حمايت اجتماعى و رفتارهاى خودمراقبتى دوران باردارى قبل و بعد از

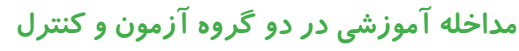

\begin{tabular}{|c|c|c|c|c|}
\hline \multirow{2}{*}{ سطح معنادارى } & بعد از مداخله & قبل از مداخله & \multirow{2}{*}{ كروه } & \multirow{2}{*}{ متغير } \\
\hline & ميانغين(انحراف معيار) & ميانگين(انحراف معيار) & & \\
\hline * $\mathrm{p}<\cdot / \cdot \cdot 1$ & $1 Q / G \cdot(\cdot / V Y)$ & $\mid \Psi / \wedge G(r)$ & آزمون & \multirow{2}{*}{ حساسيت درى شده } \\
\hline $\mathrm{p}=\cdot / \cdot 4$ & $\mid r / \Delta \Psi(\mid / \wedge \Delta)$ & $\mid r / V \Psi(\mid / \wedge \Delta)$ & كنترل & \\
\hline $\mathrm{p}<\cdot / \cdot \cdot 1$ & $\mid \Delta / \cdot V(1 / r \Delta)$ & $1 \cdot / \Delta r(r / \Delta S)$ & آزمون & \multirow{2}{*}{ شدت درك شده } \\
\hline $\mathrm{p}=\cdot / s q \mu$ & $1 \cdot / \mathscr{F V}(Y / \mid \Psi)$ & $1 \cdot / \mathscr{F}(Y / Y \Delta)$ & كنترل & \\
\hline $\mathrm{p}<\cdot / \cdots 1$ & if & $\mid r / \mu V(\mid / \mathcal{F} \varphi)$ & آزمون & \multirow{2}{*}{ منافع درى شده } \\
\hline $\mathrm{p}=\cdot / \mu F r$ & $\mid r / F F(Y / \Delta F)$ & $\mid r / 4 \cdot(1 / \Delta \Delta)$ & كنترل & \\
\hline $\mathrm{p}<\cdot / \cdot \cdot 1$ & $s / 1 \Delta(r / \Gamma \Delta)$ & $\Lambda / \Psi \vee(r / \Lambda \Gamma)$ & آزمون & \multirow{2}{*}{ موانع درك شده } \\
\hline $\mathrm{p}=\cdot / r \cdots$ & $N / 91(r / 91)$ & $\Lambda / \mu I(r / \cdot \Delta)$ & كنترل & \\
\hline $\mathrm{p}<\cdot / \cdots 1$ & $\mid r / \mathcal{F r}(\cdot / \wedge r)$ & $9 / \mathrm{V}(1 / \Delta \Lambda)$ & آزمون & \multirow{2}{*}{ خود كار آمدى } \\
\hline $\mathrm{p}=\cdot / \mu \cdot \Delta$ & $q / \cdot F(1 / \Delta \Delta)$ & $9 / \mu \Gamma(1 / \Delta S)$ & كنترل & \\
\hline $\mathrm{p}<\cdot / \cdot \cdot 1$ & $\mid Q / \Lambda F(\cdot / F Y)$ & $1 \cdot / \mathrm{V} I(1 / \mathrm{Al})$ & آزمون & \multirow{2}{*}{ حمايت اجتماعى } \\
\hline$p=\cdot / 19$ & $1 \cdot / r Y(Y / T r)$ & $1 \cdot / G \Gamma(1 / r \Delta)$ & كنترل & \\
\hline $\mathrm{p}<\cdot / \cdots 1$ & $1 \Delta / V V(1 / \Delta r)$ & $\mid r / S Y(Y / S \Psi)$ & آزمون & \multirow{2}{*}{ خود مراقبتى } \\
\hline $\mathrm{p}=\cdot / 19$ & $\mid r / F G(\mid / G F)$ & $\mid r / s \cdot(1 / \Delta \Delta)$ & كنترل & \\
\hline
\end{tabular}

باردارى مى تواند در بهبود نتايج حاملكى و تولد مؤثر باشد. نتايج

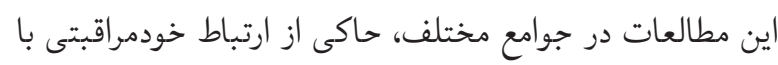

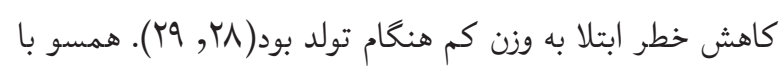

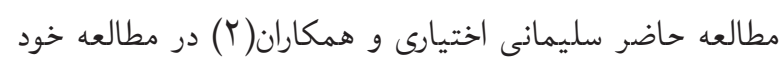

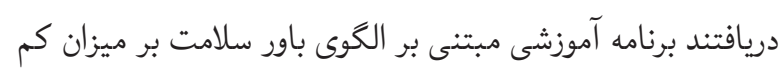

$$
\text { وزنى هنگام تولد مؤثر است. }
$$

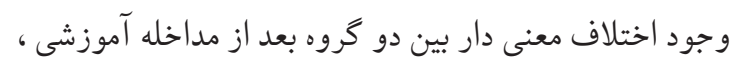

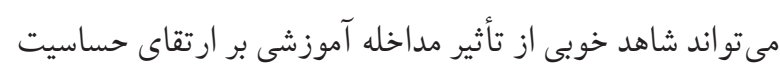

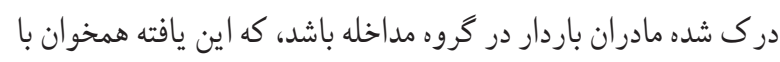

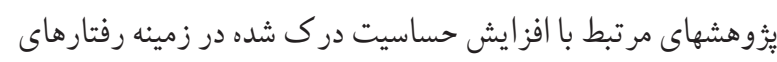

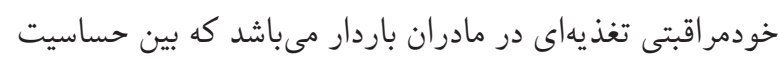
درك شده و رفتار خودمراقبتى رابطه مستقيم وجود داشت. عدم

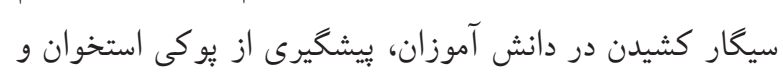

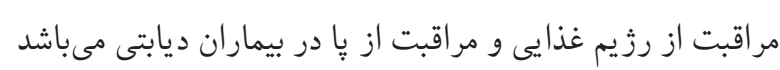

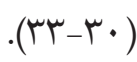

وزن در گروه آزمون كمتر بوده كه حاكى از نتيجه بهتر در گروه

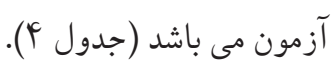

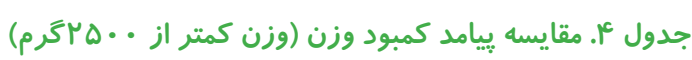

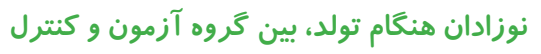

\begin{tabular}{|c|c|c|c|c|}
\hline سطح معنى & (درصد)تعداد & 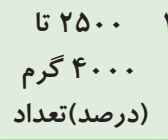 & 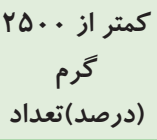 & كروه \\
\hline \multirow{3}{*}{$\cdot / \cdot \mu c=p$} & $F \Delta(\% 1 \ldots)$ & $\operatorname{Fr}(\% q \mu / \mu r)$ & $r(\%, / \varsigma \varsigma)$ & آزمون \\
\hline & $r \Delta(\% 1 \ldots)$ & $r \Delta(\% \vee V / V \vee)$ & $1 \cdot(\% r Y / r Y)$ & كنترل \\
\hline & $9 \cdot(\% 1 \ldots)$ & $\checkmark V(\% \wedge \Delta / \Delta \Delta)$ & $\| \mu(\% \mid F / F F)$ & كل ل \\
\hline
\end{tabular}
در يُوهش حاضر، ساختارهاى الخوى باور سلامت، حمايت اجتماعى

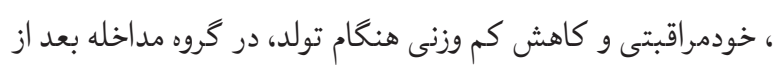

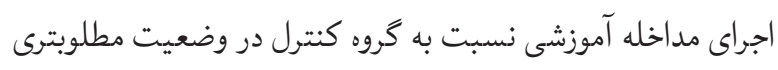
قرار كرفت. مطالعات مشابه نشان دادهاند كه خودمراقبتى دوران 
خود كار آمدى، درك ذهنى فرد از تونايى هايش براى انجام

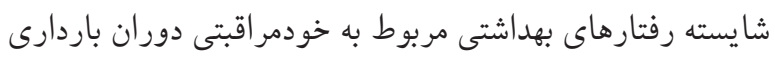

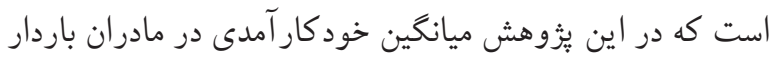

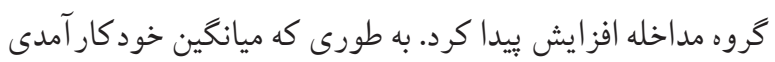

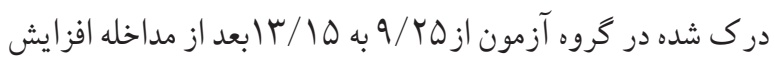

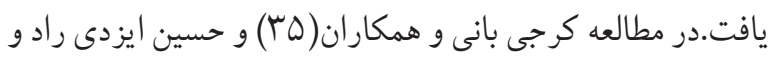

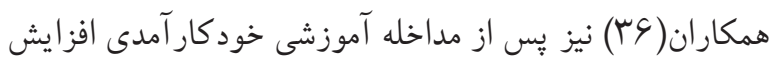

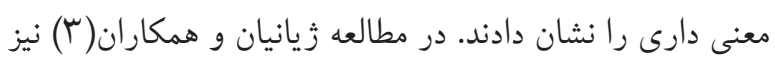

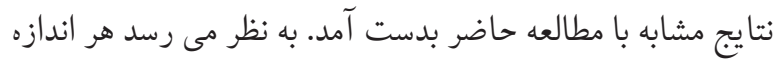

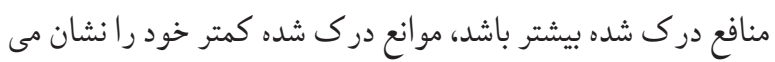

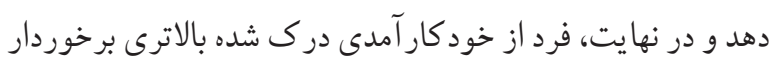

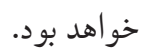

همجنين، يافتهاى يُزوهش حاضر، حاكى است ميزان حمايت اجتماعى در گروه مداخله بطور معنى دارى بيشتر از گروه كنترل

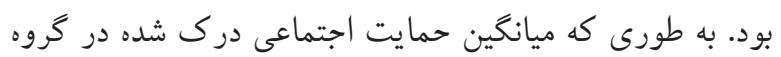

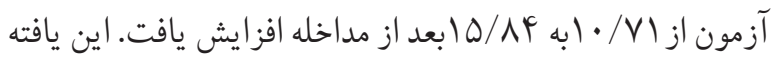

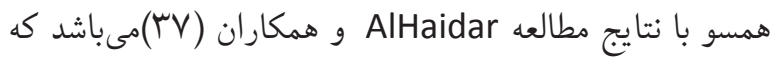
حمايت اجتماعى خانواده در زمينه خودمراقبتى در كروه مداخله

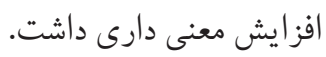

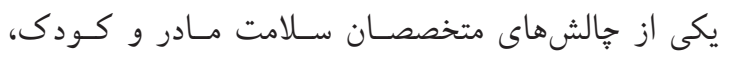

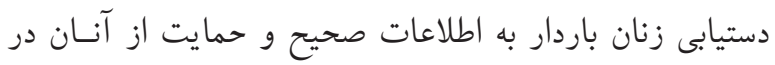

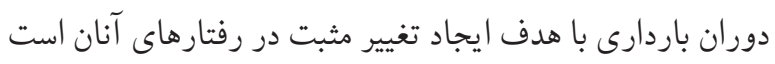

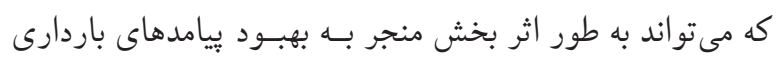

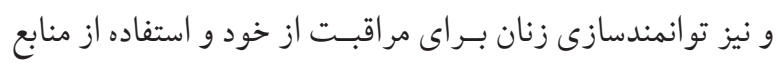

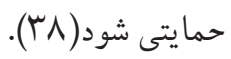
ايسن امــر بيـانكر آن است كه علاوه بر اينكه زنان بـاردار نيـاز بــه حمايـت اجتماعى بالاترى دارند در زنان باردار يرخطر اين نياز

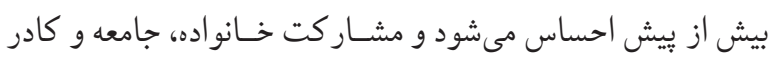

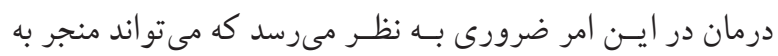

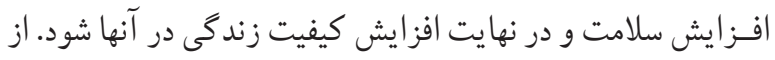
طرفى انزواى اجتماعى باعث مىشود افراد به سختى الكوهاى رفتارى
از لحاظ شدت درك شده افزايش ميانكين نمره شدت درى

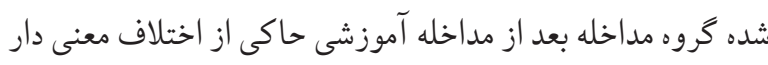
در شدت درك شده بين دو گروه بود، به طورى كه ميانگين شدت

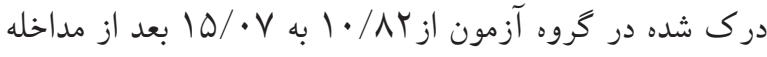
افزايش يافت. افزايش شدت درك شده در ساير مطالعات مشابه

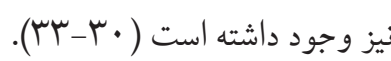

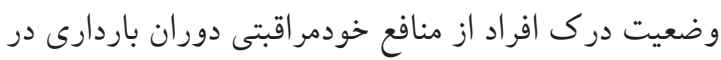

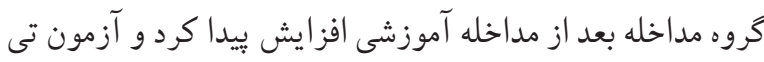

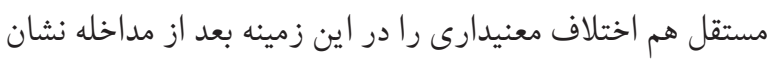
داد. به طورى كه ميانگين حساسيت درك شده در گروه آزمون

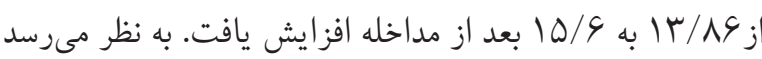

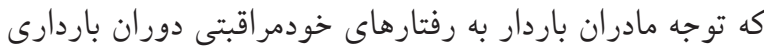

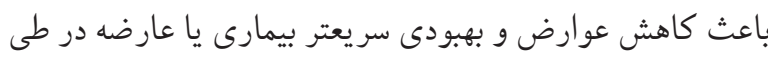

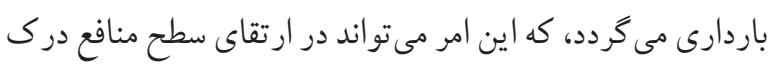

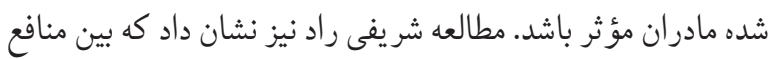

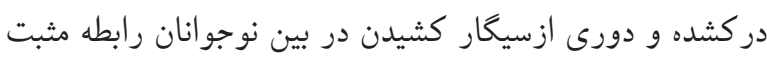
وجود دارد (Yr). وضعيت درك مادران از موانع موجود جهت خودمراقبتى دوران

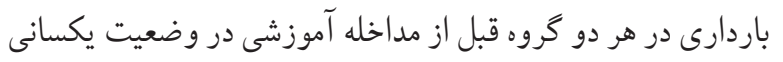

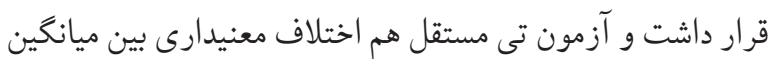
نمره موانع دركشده در دو كروه نشان نداد؛ به طورى كه ميانگين

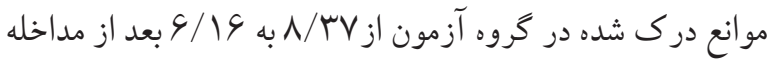

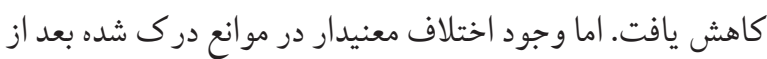

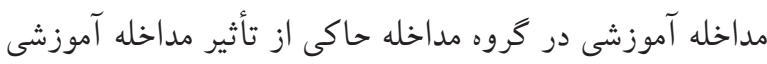
بر رفع موانع دركشده در خصوص خودمراقبتى در گروه مداخله بوده است. يكى از موانع مهم مطرح شده كمبود وقت بود كه با

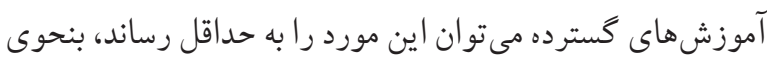
كه در مطالعه شريفى راد نيز با كاهش موانع در كشده، نوجوانان

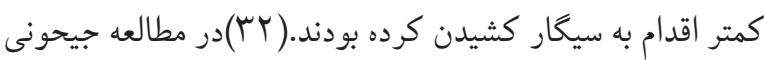

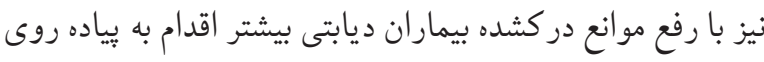

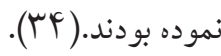


سلامت و ساختار حمايت اجتماعى در گروه آزمون، بطور معنادارى موجب افزايش رفتارهاى مراقبتى دوران باردارى و كاهش تولد نوزاد

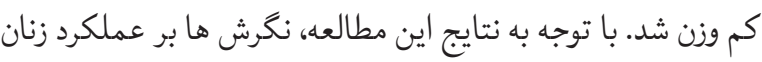
در دوران باردارى موثر مى باشد به طورى كه افزايش حساسيت،

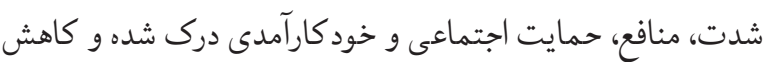

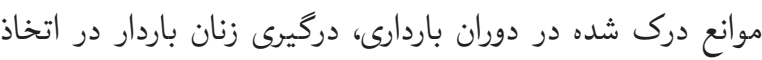

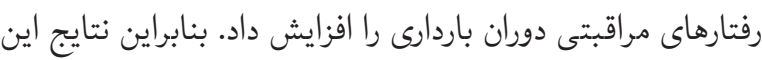

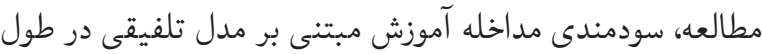

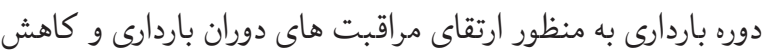
ييامد نامطلوب وزن كم هنگام تولد را نشان داد. با توجه به محدود بودن گروه هدف به زنان باردارشكم اول در ورد

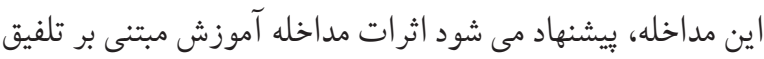

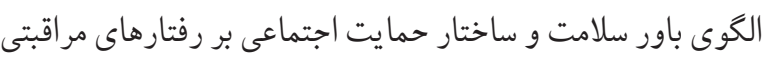

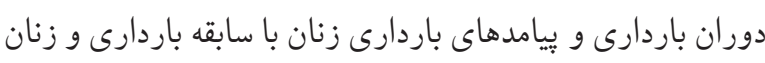

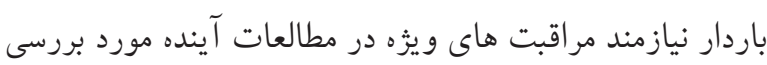

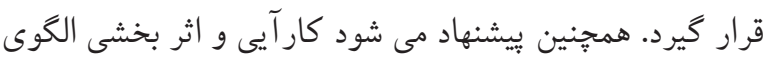
باور سلامت و ساختار حمايت اجتماعى در مقايسه با كار آيى ساير

$$
\text { مدل ها و تئوريها بررسى شود. }
$$

يُزوهشگران مراتب سياس خود را ازهمكارى ارزنده مسئولين دانشگاه

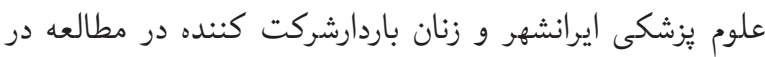
راستاى ارتقاى ييشرفت علمى كشور ابراز مى دارند.

\section{Refrences}

1.Gaiva MAM, Palmeira EWM, Mufato LF. Women's perception of prenatal and delivery care in cases of neonatal death. Esc Anna Nery. 2017;21(4):e20170018. https://doi.org/10.1590/2177-9465-ean-2017-0018

2.Solhi M, Abbasi K, Ebadi Fard Azar F, Hosseini A. Effect of Health Literacy Education on Self-Care in Pregnant Women: A Randomized Controlled Clinical Trial. IJCBNM.2019;7(1):2-12.

3.Ekhtiari YS MF, Foroushani AR, Shakibazadeh E. Effect of a Self-care Educational Program Based on the Health Belief Model on Reducing Low Birth Weight Among Pregnant Iranian Women. Int J Prev Med. 2014;5(1):76-82.

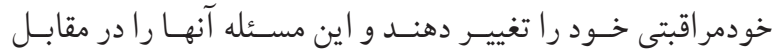
شــايط حسـاس مثـل دوران باردارى، زايمان و پِّ از زايمان

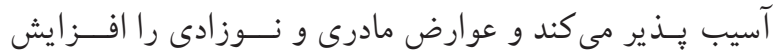

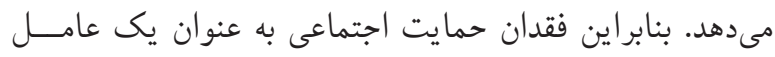

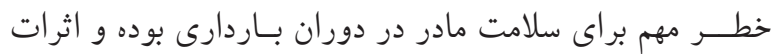

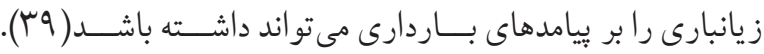

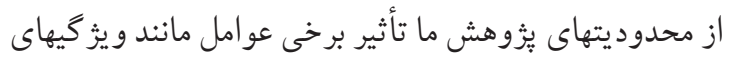

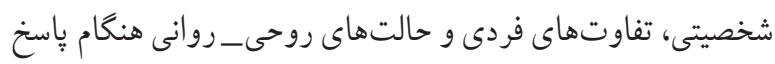

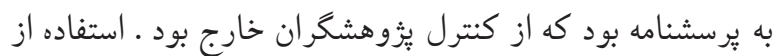

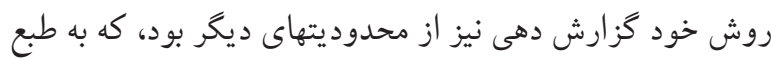

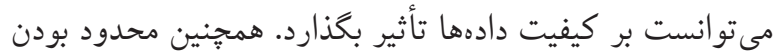

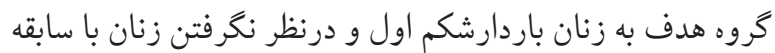
باردارى از ديكر محدوديت هاى مطالعه اضر مى باشد. در مطالعه حاضر،در نظر كرفتن حمايت اجتماعى (عاطفى، اطلاعاتى و اقتصادى) در خودمر اقبتى زنان باردار، مى تواند به عنوان يك نقطه مثبت در نظر كرفته شود، زيرا رفتارهايى مانند فعاليت فيزيكى، تغذيه و رعايت بهداشت دهان و دندان توسط گستره وسيعى از متغيرهاى اجتماعى، روانى و اقتصادى تعيين مىشود.

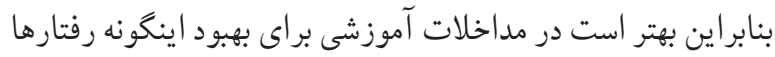
در افراد به اين عوامل برداخته شود. نتيجه كيرى در يُزوهش حاضر، مداخله آموزشى مبتنى بر تلفيق الكوى باور

4. Ekhtiari YS MF, Foroushani AR, Shakibazadeh E. Effect of a Self-care Educational Program Based on the Health Belief Model on Reducing Low Birth Weight Among Pregnant Iranian Women. Int J Prev Med. 2014;5(1):76-82. https://doi.org/10.22038/jhl.2020.46110.1097

5.Moraes AN, Likwa RN, Nzala SH. A retrospective analysis of adverse obstetric and perinatal outcomes in adolescent pregnancy: the case of Luapula Province, Zambia. Maternal Health, Neonatology, and Perinatology. 2018: 4(20);2-11. https://doi.org/10.1186/s40748-018-0088-y PMid:30349732 PMCid:PMC6192102

6.Harrison AL, Taylor NF, Shields N, Frawley HC . 
Attitudes, barriers and enablers to physical activity in pregnant women: a systematic review. Journal of Physiotherapy. 2018: 64: 24-32. https://doi.org/10.1016/j.jphys.2017.11.012 PMid:29289592

7.Yasuoka J, Nanishi K, Kikuchi K, Suzuki S, Ly P, Thavrin B, et al. Barriers for pregnant women living in rural, agricultural villages to accessing antenatal care in Cambodia: A community-based cross-sectional study combined with a geographicinformationsystem. PLoSONE.2018:13(3):1-20. https://doi.org/10.1371/journal.pone.0194103 PMid:29554118 PMCid:PMC5858830

8. Heidarzadeh $M$, Jodeiry B, Hosseini MB, Mirnia K, Akrami F, Habbibollahi A. High Risk Infants FollowUp: A Case Study in Iran. International Journal of Pediatrics. 2015:1-6. doi.org/10.1155/2015/817540 https: / / d o i.org / $10.1155 / 2015 / 817540$ PMid:26136787 PMCid:PMC4468300

9.Cutland $\mathrm{CL}$, Lackritz EM, Mallet-Moore T, Bardaji A, Chandrasekaran R, Lahariya C, et al. Low birth weight: Case definition \& guidelines for data collection, analysis, and presentation of maternal immunization safety data. Vaccine. 2017; 35(48): 6492-6500. https://doi.org/10.1016/j.vaccine.2017.01.049 PMid:29150054 PMCid:PMC5710991

10. Mahmoudi Zadeh M, Nemati E, Rezaei F, Sharafi H. The prevalence of premature and low weight neonate birth and risk factors in operating room staffs of Bandarabbas educational hospitals. Zanko J Med Sci. 2017; 18 (58) :6167.

11.Mbuagbaw L, Medley N, Darzi AJ, Richardson M, Habiba Garga K, Ongolo-Zogo P. Health system and community level interventions for improving antenatal care coverage and health outcomes. Cochrane Database Syst Rev. 2015;(12) . https://doi.org/10.1002/14651858.CD010994.pub2 PMid:26621223 PMCid:PMC4676908

12. Atkins DN, Barroso CS, Anderson AJ, Meadows JT, Lindley LC. Maternal Health of Undocumented Women with and Without Medicaid Access in Nebraska, 2007-2011. Hispanic Health Care International. 2017:15(1);1-10. https://doi.org/10.1177/1540415316682722 PMid:28558512

13.Shin D, Song WO. Influence of the Adequacy of the Prenatal Care Utilization Index on Small-ForGestational-Age Infants and Preterm Births in the United States. J Clin Med. 2019, 8(6), 838. h tt p s: / / doi.org/10.3390/jcm8060838 PMid:31212823 PMCid:PMC6616923

14. Vahedian-Shahroodi M, Tehrani H, Robat-Sarpooshi D, Gholian - Aval M, Jafari A, Alizadeh-Siuki H. The impact of health education on nutritional behaviors in female students:anapplication ofhealthbeliefmodel.International
Journal of Health Promotion and Education. 2019:1-13. https://doi.org/10.1080/14635240.2019.1696219

15.Aygar $H$, Akbulut Zencirci S, Ozturk Emiral G, Alaiye $M$, Soysal A, Onsuz MF, et al. Assessment of healthpromoting lifestyle behaviors of adults living in the semi-rural area. North Clin Istanbul 2019;6 (1): 13-20. https://doi.org/10.14744/nci.2017.19327 PMid:31180385 PMCid:PMC6526993

16. Schaffler J, Tremblay S, Lambrou A. The Effectiveness of Self-Management Interventions for Individuals with Low Health Literacy and/or Low Income: A Descriptive Systematic Review. J Gen Intern Med2018: 33 (4): 510-23. https://doi.org/10.1007/s11606-017-4265-x PMid:29427178 PMCid:PMC5880764

17. Emamgholi Khooshehchin T, Keshavarz Z, Afrakhteh M, Shakibazadeh A, Faghihzadeh S. Explanation the experiences of mothers with gestational diabetes about the factors affecting self-care: A qualitative study. Journal of Clinical Nursing and Midwifery. 2017; 5 (4):76-89.

18.Ginja S, Coad J, Bailey E, Kendall S, Goodenough T, Nightingale $S$, et al. Associations between social support, mental wellbeing, self-efficacy and technology use in firsttime antenatal women: data from the BaBBLeS cohort study. BMC Pregnancy and Childbirth, 2018: 18:441;2-11. https://doi.org/10.1186/s12884-018-2049-x PMid:30419842 PMCid:PMC6233574

19.Baker B, Yang I. Social media as social support in pregnancy and the postpartum. Sexual \& Reproductive Health Care. 2018:17:31-34. https://doi.org/10.1016/j.srhc.2018.05.003 PMid:30193717

20-Moosavinasab MS, Fahami F, Kazemi A. The Relationship between Cognitive Social Theory and Physical Activity in Pregnant Women. Int J Pediatr 2018; 6 (11): 8527-35.

21. Izadirad H, Niknami S, Zareban I, Hidarnia A. Effects of Social Support and Self-Efficacy on Maternal Prenatal Cares Among the First-Time Pregnant Women, Iranshahr, Iran. J Fam Reprod Health 2017; 11(2): 67-73.

22.Chasse JD. Reducing Infant Morbidity with Adolescent Mothers. Obstet Gynecol Int J. 2017: 8(2): 1-6. https://doi.org/10.15406/ogij.2017.08.00283

23.Mohebi S, Parham M, Sharifirad G, Gharlipour Z, MohammadbeigiA, RajatiF. Relationshipbetweenperceived social support and self-care behavior in type 2 diabetics: A cross-sectional study. J Educ Health Promot. 2018;7:48. https://doi.org/10.4103/jehp.jehp_73_17 PMid:29693029 PMCid:PMC5903155

24. Torkan N, Kazemi A, Paknahad Z, Bahadoran P4 Relationship of Social Cognitive Theory Concepts to Dietary Habits of Pregnant Women. Iran J Nurs Midwifery Res. 2018;23(2):125-130.

25. Ahmadpoor H, Maheri A, Shojaizadeh D. Effectiveness of 
Nutrition Education Based on Health Belief Model during Pregnancy on Knowledge and Attitude of Women Referred to Health Centers of Gonbad Kavoos City. J Neyshabur Univ Med Sci 2015; 3 (2) :52-60.

26. Momeni Javid F, Simbar M, Dolatian M, Alavi Majd H. Comparison of Pregnancy Self-Care, Perceived Social Support and Perceived Stress of Women with Gestational Diabetes and Healthy Pregnant Women. Int J Endocrinol Metab 2014;16(3):162-9. https://doi.org/10.5539/gjhs.v7n2p162 PMid:25716401 PMCid:PMC4796349

27. Izadirad H, Niknami SH, Zareban I, Hidarnia A, Ansari Moghadam A. Designing and Developing the Prenatal Care Scale based on Health Belief Model. Health Education and Health Promotion (HEHP), 2015; 3 (3): 29-42.

28. Evaluating the quality of antenatal care and pregnancy outcomes using content and utilization assessment. International Journal for Quality in Health Care,2018:30(6): 466-471. https://doi.org/10.1093/intqhc/mzy041 PMid:29590356

29. Kharazi SS, Peyman N, Esmaily H. The Relationship between Maternal Health Literacy and Dietary SelfEfficacy with Pregnancy Outcomes. Journal of Midwifery and Reproductive Health. 2020; 8(1): 2058-2068.

30. Shabibi P, Abedzadeh Zavareh MS, Sayehmiri K, Qorbani M, Safari O, Effect of educational intervention based on the Health Belief Model on promoting self-care behaviors of type-2 diabetes patients. Electronic physician, 2017:9(12); 5960-5968. h tt p s: / / d o i.org / $10.19082 / 5960$ PMid:29560148 PMCid:PMC5843422

31. Sadeghi Goorabi M, Akhoundan M, Shadman Z, Hajifaraji M, Khoshniat Nikoo $M$.The Effect of Nutritional Education Program Based on Health Belief Model (HBM) on the Knowledge of Fasting Type 2 Diabetic Patients. Nutrition and Food Sciences Research. 2017:4(2): 15-23. https://doi.org/10.18869/acadpub.nfsr.4.2.3
32. Khazaee-Pool M, Zarei F, Pashaei T, Shojaeizadeh D. The effect of an educational intervention based on health belief model on improving smoking preventive behaviors among students. Iranian Journal of Health Education and Health Promotion. 2017;4(4):300-8. https://doi.org/10.18869/acadpub.ihepsaj.4.4.300

33. Khani Jeihooni A, Askari A, Kashfi SM, Khiyali Z, Kashfi $\mathrm{SH}$, Safari O, et al. Application of Health Belief Model in Prevention of Osteoporosis among Primary School Girl Students. Int J Pediatr 2017; 5(11): 6017-29.

34. Khani Jeihooni A, Askari A, Kashfi SM, Khiyali Z, Kashfi $\mathrm{SH}$, Safari O, et al. Application of Health Belief Model in Prevention of Osteoporosis among Primary School Girl Students. Int J Pediatr 2017; 5(11): 6017-29.

35. Karajibani M, Montazerifar F. The Effect of Nutritional Education on Knowledge and Practice at the Household Level in Zahedan. JNFS. 2019; 4 (1) :17-25 https://doi.org/10.18502/jnfs.v4i1.396

36. Izadirad H, Niknami Sh, Zareban I \& Hidarnia AR. Improving prenatal care in pregnant women in Iranshahr, Iran: Applying Health BeliefModel. Women \& Health. 2018;58(10):1167-1178. https://doi.org/10.1080/03630242.2017.1388333 PMid:29111919

37. AlHaidar AM, AlShehri NA, AlHussaini MA. Family Support and Its Association with Glycemic Control in Adolescents with Type 1 Diabetes Mellitus in Riyadh, Saudi Arabia. Journal of Diabetes Research, 2020:1-6. https://doi.org/10.1155/2020/5151604 PMid:32280715 PMCid:PMC7125464

38. Mousavi Chalac A, Riahi A. Information Needs of Pregnant Women Referred to Health Centers in Behshahr City during 2016-17. JCHR. 2017; 6 (3) :165-174

39. Borghei NS, Taghipour A, Latifnejad Roudsari R. [Pregnant mothers' strategies for the management of pregnancy concerns]. Hayat, Journal of School of Nursing and Midwifery, Tehran University of Medical Sciences. 2017; 23(2): 106-125. 